\title{
Los Desafios del Derecho Civil en el Mercosur
}

\author{
Claudia Schmidt $\mathcal{H}_{\text {ott }}$
}

Profesora de Derecho Civil, Facultad de Derecho, Universidad de Chile

\section{CONGRESO NACIONAL Y VII LATINOAMERICANODEDERECHOPRIVADOEN HOMENAJE AL PROFESOR, DOCTOR ROBERTO MANUEL LÓPEZ CABANA}

Facultad de Derecho, Universidad de Buenos Aires, 7, 8 y 9 de junio del 2001

\section{Privatización del ius civile}

$1 F_{1}$ erecho Civil o Derecho del civis (ciudadano) o Derecho de la cívitas (ciudad), y más específicamente el Derecho del ciudadano romano no fue un Derecho esencialmente Privado, sino que, como es sabido, dentro de concepto ius civile, además del Derecho Romano se incluían temas que hoy cabrían dentro del Derecho Procesal, Penal o Administrativo. Señala Carlos Martínez de Aguirre y Aldaz que el Derecho Civil "en determinados momentos del proceso de su formación histórica fue más aún que sólo Derecho Privado". ${ }^{1}$ El proceso privatizador del Derecho Civil lo encontramos a lo largo de la Edad Media, como consecuencia de la desaparición de las estructuras sociopolíticas propias del imperio romano, que constituían el presupuesto necesario para la aplicación de los textos del Corpus Iuris. ${ }^{2}$ En consecuencia, la denominación "Derecho Civil" desde este punto de vista resulta más histórica que dogmática.
Sin embargo, teniendo en cuenta su contenido, es el Derecho privado general y común, toda vez que se ocupa de la persona, y por ende de la familia, y del patrimonio, dando lugar a subramas, como lo son los Derechos Reales que junto al Derecho de Familia, importan el presupueto esencial del Derecho Sucesorio; el Derecho Obligacional que junto a los Derechos Reales, constituyen el estudio del patrimonio; el Derecho General de los Contratos y muy especialmente el Derecho de Daños que se proyecta tanto en el campo del Derecho Privado Patrimonial como Extrapatrimonial. Diremos por el momento, porque a ello nos abocaremos más adelante, que las ramas del Derecho Civil son transversales dentro del Derecho Privado y dentro del Derecho Público, ramas estas últimas cuyas fronteras cada día se desdibujan más. Así por ejemplo, el penalista debe conocer desde y hasta cuando se extiende la vida del ser humano, qué se entiende por propiedad y cuales son sus limitaciones inmanentes y no inmanentes, qué son los títulos de mera tenencia, quées el parentesco y cuáles son sus parámetros de medición, etc.

'MARTINEZ DE AGUIRRE Y ALDAZ, El Derecho Civil a finales del Siglo XX, Editorial Tecnos S.A., Madrid 1991, pág. 17.

2 Díez-Picazo, El Sentido Histórico del Derecho Civil, RGLJ, 1959-2, pp. 621 y ss. 
II. La codificación del derecho privado en el siglo XIX

Algunas de las palabras del codificador chileno perfectamente podrían constituir hoy, las palabras del mensaje o moción de un nuevo Código Civil. Señalaba don ANDRÉS BELLOLÓPEZ:" "Muchos pueblos modernos más civilizados han sentido la necesidad de codificar sus leyes. Se puede decir que ésta es una necesidad periódica de las sociedades. Por completo y perfecto que se suponga un cuerpo de legislación, la mudanza de costumbres, el progreso mismo de la civilización, las vicisitudes políticas, la inmigración de ideas nuevas, precursora de nuevas instituciones, los descubrimientos científicos y sus aplicaciones a las artes y a la vida práctica, los abusos que introduce la mala $f e$, fecunda de arbitrios para eludir las precauciones legales, provocan sin cesar providencias, que se acumulan a las anteriores, interpretándolas, adicionándolas, modificándolas, derogándolas, hasta que por fin se hace necesario refundir esta masa confusa de elementos diversos, incoherentes $y$ contradictorios, dándoles consistencia y armonía y poniéndoles en relación con las formas vivientes del orden social." Sin embargo, cuando uno recorre el Mensaje de nuestro

codificador, va palpando cómo se han alejado muchos de sus principios fundamentes a los nuevos principios que han de informar un Código Civil del siglo XXI, porque tal como dijo Bello" "LA CODIFICACIÓN ES UNA NECESIDAD PERIÓDICA DE LAS SOCIEDADES."

Inicia el proceso codificador el Código Napoleónico de $1804{ }^{5}$ que ejerció gran influencia en otros códigos pertenecientes al grupo occidental de sistema legal, como lo fueron los de Bélgica, Luxemburgo, República Dominicana, Italia de 1865, España de 1889 , Portugal de 1867 y desde luego en el ámbito latinoamericano, los Códigos de Bolivia promulgado el 2 de abril de 1831, que rigiera 145 años, de Uruguay promulgado el 23 de enero de 1868, de Paraguay adoptado por leyes de 1876 y 1889 , y el vuestro, en que el ilustre jurisconsulto Dalmacio Vélez Sarsfield al remitirlo al Ministerio de Justicia el 21 de junio de $1865,{ }^{6}$ manifestó que para su trabajo se sirvió, principalmente entre otros códigos, del Código de Chile, que a su juicio, aventajaba a los códigos europeos. ${ }^{7}{ }^{8}$ Sin embargo, debo señalar, que hoy nuestro Código Civil demuestra un retraso de al menos 30 años dentro del contexto latinoamericano. Así por ejemplo, en e ámbito del Derecho de las Personas no consi-

${ }^{3}$ Mensaje del Ejecutivo al Congreso porponiendo la aprobación del Código Civil, Santiago de Chile, noviembre 22 de 1855.

${ }^{4}$ Don Andrés Bello López llegó a Chile en 1829 y se le concedió la nacionalidad chilena por gracia del Congreso Nacional en 1832, fue Senador de la República y primer rector de la Universidad de Chile, falleció en Santiago a los 84 años de edad. Fue jurista, poeta, filólogo e internacionalista, más no fue abogado, pues dada la muerte de su padre, debió abandonar sus estudios de Derecho a los 20 años para sostener a su madre y siete hermanos menores.

${ }^{5}$ Sin perjuicio que le anteceden el Código austríaco de 1811 y del Código Civil prusiano de 1874.

${ }^{6}$ Promulgado el 25 de septiembre de 1869 por Ley $\mathrm{N}^{\circ} 340$ y con vigencia desde el $1^{\circ}$ de enero de 1871 .

${ }^{7}$ Por su parte siguieron al Código Civil chileno los Códigos de Ecuador y Colombia y también, aunque en parte menos considerable el Código Civil del Uruguay de 23 de enero de 1868.

${ }^{8}$ Vodanovic Antonio H., Derecho Civil, Parte Preliminar y Parte General, Explicaciones basadas en las versiones de clases de los profesores de la Universidad de Chile Arturo Alessandri R. y Manuel Somarriva U., Quinta Edición, Ediar Conosur Ltda., Santiago de Chile, 1990.

Revista da Faculdade de Direito da UFRGS, v. 20, Outubro/2001

dera tales, a la criatura por nacer, cuestión que ya entonces criticaba Vélez Sarsfield ${ }^{9}$ y, establece que son absolutamente incapaces los sordomudos que no pueden darse a entender por escrito; en el ámbito del Derecho de Familia, contempla un sistema económico patrimonial antidemocrático en el cual, la mujer casada bajo el régimen legal y supletorio de sociedad conyugal, si bien tiene la propiedad de sus bienes, le está vedado su uso, goce, administración y disposición y, no contempla un ejercicio compartido de la autoridad parental tratándose de progenitores que viven juntos; en el ámbito del Derecho Patrimonial, entre tantas falencias, aún no da cabida a la revisión o resolución de los contratos por excesiva onerosidad sobreviniente, ${ }^{10}$ no contempla normas sobre cláusulas abusivas dentro de los contratos de adhesión, a los cuales, ni siquiera se refiere, salvo por alguna norma en materia de interpretación contractual; ${ }^{11} \mathrm{y}$, contempla la lesión con aplicación restringida (sólo 7 casos) y con un carácter estrictamente objetivo.

\section{El derecho civil: derecho privado y general}

El Derecho Privado no se agota en e Derecho Civil, pues dentro del Derecho Privado coexisten los Derechos Privados Especiales que nacen como una respuesta de regulación para relaciones jurídicas privadas entre personas no consideradas en cuanto tales, sino que por determinadas calificaciones, como por ejemplo, la de comerciante, trabajador, consumidor, niño y adolescente, etc. dando lugar a estatutos jurídicos diferenciados, fundados en principios particulares, pero que en caso alguno importan el alejamiento de la columna vertebral del Derecho Privado General y Común, pues antes de ser comerciante, trabajador, consumidor, niño o pariente, se es persona, pues como señala CARLOS FERNANDEZ SESSAREGO “la persona debe ser considerada como fin en sí misma y no como medio. Es por ello que jurídicamente no existe un interés superior al de la protección de la persona en cuanto protagonista del Derecho». ${ }^{12}$ Se formulan así el Derecho Comercial, el Derecho Bancario, el Derecho del Niño y/o Adolescente, el Derecho Ambiental, el Derecho del Consumidor, el Derecho Aeronáutico, el Derecho Indígena, el Derecho Registral, el Derecho Informático, etc. Sin embargo, estos Derechos Privados especiales destinados a personas que se encuentran en una determinada situación jurídica, no se apartan en lo medular del Derecho Privado General Es más, algunos de ellos, como el Derecho Mercantil, vuelven a formar parte del Código de Derecho Privado General, y en este aspecto, puede hablarse de la comercialización del Derecho Privado

${ }^{9}$ En relación al art. 63 del Código Civil argentino, señalaba Vélez Sarsfield: Las personas por nacer no son ción al art. 63 del Código Civil a re habría sujeto que personas futuras, pues ya existen en el 74 ć́digo Civil chileno, sén el cul la personalidadjurídica comienza representar. Agregaba criticando el art. 74 del Codigo Civil chileno, según el cúl, la perso pen con el nacimiento, porqué si lo que aún no han nacido no so personas, porque las leyes penales castigan el aborto premeditado y porqué no se puede ejecutar una pena en una mujer embarazada?

${ }^{10}$ Sin perjuicio que en la actualidad se encuentra para primer trámite constitucional dentro de la Comisión de Constitución. Legislación y Justicia de la Cámara de Diputados, un proyecto de Ley que permite la revisión judicial de los contratos civiles y mercantiles. Boletín No 309-07.

11 Ver art. 1566 del Código Civil chileno.

12 Derecho y Persona, Lima 1990, pág. 103. Citado por ALTERINI, ATILIO A. y LOPEZ CABANA, ROBERTO M., en

Cuestiones de Responsabilidad Civil en el Derecho de Familia, Derecho de Daños, La Ley, Buenos Aires 1992, pág. 241. 
Patrimonial. ${ }^{13}$ En este contexto, vuestra experiencia es notable. Señala el Doctor Atilio A. Alterini que, "en Argentina se intentó una y otra vez reformar los Códigos del Derecho Privado, con la idea básica de unificarlos y de modernizarlos bajo la forma del denominado Derecho Privado, o Derecho Privado Patrimonial" ${ }^{14}$ y dentro de ese contexto se enmarca el proyecto de Código Civil de 1998 que cuenta con 2532 artículos. Esta idea unificadora del Derecho Privado Patrimonial se consagra en el Código Italiano de 1942, que se agrupa dentro de los códigos civiles modernos y también en el Código Civil peruano de 1984 que comienza el inicio de la unificación de las reglas del Derecho Civil y del Derecho Comercial, especialmente en materia de actos jurídicos, obligaciones y contratos civiles y mercantiles. ${ }^{15}{ }^{16}$ Pero tal como señala el doctor Alterini, para determinar si la unificación es posible es necesario constatar si se han incorporado al Código Civil los principios propios de los contratos comerciales, como por ejemplo, la fuerza jurídica de los usos. En consecuencia, en mi opinión los países de la región pueden encontrarse en diferente grado de madurez sobre el particular. Sin embargo, creo que han de volver al Código Civil, como cuerpo normativo que representa la columna vertebral del Derecho

Privado, muchos de los Derechos Privados especializados. Por de pronto postulo a una unificación parcial del Derecho Civil y Comercial en lo atingente al Derecho de Obligaciones y al Derecho Contractual, unificación que se impone frente al proceso de globalización e internacionalización. Pero así como postulo a esta unificación, también me asiste el convencimiento que el Derecho Privado General, esto es el Derecho Civil dentro de un proceso recodificador, no puede abandonar el Derecho de Familia y sus problemas emergentes, como tampoco, el Derecho de las Personas desde la perspectiva del respeto de sus derechos humanos o derechos de la personalidad. Es así como puede apreciarse que algunos países han separado de la recodificación civil el Derecho de Familia a través de un Código de Familia como en el caso de Bolivia. ${ }^{17}$ En este mismo sentido, si bien la característica actual del Derecho a la Niñez es su codificación, como ha sucedido en Bolivia, Brasil, Colombia, Costa Rica, Ecuador, El Salvador Guatemala, Paraguay, Perú, Uruguay, Venezuela, siendo los más recientes los de Bolivia de 1992, Brasil de 1990, Colombia de 1989, Ecuador de 1992, Perú de 2000 y República Dominicana de 1994, ella está destinada a mi juicio a abordar el desarrollo legislativo de los

${ }_{13}$ Véase "La Comercialización del Derecho Civil" de LÓPEZ CABANA, ROBERTO M., en Revista de Responsabilidad Civil y Seguros dirigida por Atilio A. Alterini, Año III No I, Enero - Febrero, 2001, La Ley, Buenos Aires, Argentina.

${ }^{14}$ ALTERINI, ATILIO A., El Código Civil del Siglo XXI (Perú y Argentina), Coordinadores: Atilio A. Alterini, Carlos Alberto Soto y Jorge Muñiz Ziches, Primera Edición, págs. 38-39, Ediciones Jurídicas, Lima, Perú, 2000 ${ }^{15} \mathrm{El}$ art. 2112 del Código Civil de 1984 derogó cinco contratos contenidos en el Código de Comercio: compraventa, permuta, mutuo, depósito y fianza mercantil.

${ }^{16}$ Señala MUÑIZ ZICHES, Jorge en ob. cit. en nota 14 que: Esta idea unificadora tiene importantes antecedentes legislativos. El Código de las Obligaciones Suizo de 1881, el Código Civil Italiano de 1942 que comprende material

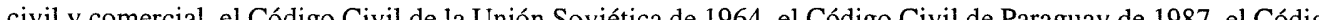
Civil Cuba de 1988, el Código Civil Hérigo Civil Cubano de 1988, écódigo Civilde Holanda de 1992, eód Códgo Civil Civilde Par de Vietnam de 1995, el Código Civil de la Federación Rusa de 1994, el Código UNICO en los Civil y Comercial de China de 1987.

${ }^{17}$ Código de Familia aprobado por Decreto Ley No 10.426 de 23 de agosto de 1972 que consta de un Título Preliminar y de Cuatro Libros, relativos al matrimonio, la filiación, la autoridad de los padres y los procedimientos, vigente desde el 26 de agosto de 1977.

Revista da Faculdade de Direito da UFRGS, v. 20, Outubro/2001 derechos fundamentales de los niños, pero los efectos jurídicos por ejemplo derivados de la filiación determinada, como la relación filial debiera particularizarse en un Código Civil moderno acogiendo la integralidad del Derecho Privado y en consecuencia, su unificación. ${ }^{18}$ En todo caso, debe tenerse presente que en general, la Convención sobre los Derechos del Niño tiene jerarquía constitucional a nivel regional. En efecto, vuestra Constitución reformada en 1994 establece en su art. $75 \mathrm{~N}^{\circ} 22$ que tiene jerarquía constitucional la Convención sobre los Derechos del Niño. No con esta misma claridad, pero sí en opinión de la doctrina mayoritaria, los tratados internacionales sobre derechos humanos tienen en nuestra carta fundamental jerarquía constitucional. En efecto, el art. 5 inciso $2^{\circ}$ de la Constitución Política de la República reformada el año 1989 estatuye: “ $E l$ ejercicio de la soberanía reconoce como limitación el respeto a los derechos esenciales que emanan de la naturaleza humana. Es deber de los órganos del Estado respetar y promover tales derechos, garantizados por esta Constitución, así como por los tratados internacionales ratificados por Chile y que se encuentren vigentes." Por su parte, en la Constitución de la República Federativa de Brasil de 1988, que ya ha tenido 22 enmiendas constitucionales en 1999, los tratados internacionales aprobados por el Congreso tienen la misma jerarquía de las normas constitucionales. En cambio la Constitución Nacional del Paraguay de 1992 le asigna a esto tratados un valor supralegal pero

infraconstitucional, dados los términos de sus art. 137 y $141 .{ }^{19}$

\section{La recodificación del dere- cho privado: un imperativo impostergable}

Se señala en el Acta de Arequipa que la "codificación es el método más adecuado para la expresión del Derecho Privado, como lo demuestra el yasto movimiento codificador" $y$ "Que la armonización en sectores relevantes del Derecho Privado es posible en América Latina por la pertenencia a la familia romanogermánica, lo que constituye un indudable factor de identidad cultural". ${ }^{20}$ En este contexto, la recodificación del Derecho Privado se nos impone como un imperativo dada la desintegración de él en diversos Derechos Privados Especiales y en atención a las leyes civiles satelitales o extracodiciales. La proliferación de estas leyes civiles especiales en nuestro país se hizo sentir ya desde el siglo XIX, cuestión que se va planteando por las falencias de los primeros códigos en diversas materias y por las nuevas realidades que se nos van presentando y que el legislador no puede ignorar. Tal vez, la proliferación de estas leyes extracodiciales se deba al hecho de que es más fácil la dictación de una ley especial, que la modificación del Código Civil, pero ha llegado el momento de recodificar y ello, muy especial-

${ }^{18}$ En este sentido puede citarse el Código del Menor de Bolivia

19 Art. 137: La ley suprema de la República es la Constitución. Ésta, los tratados, convenios y acuerdos internacionas a ley

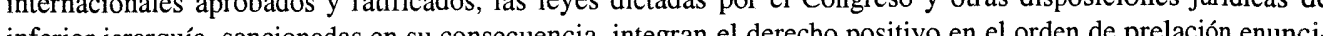
infe. Quention ado. Quienquiera queitentecalón, incurrirá en los delitos que se tipificarán y penarán en la ley. Carecen de validez todas las disposiciones y los actos de autoridad opuestos a lo establecido en esta Constitución.

${ }^{20}$ Consultada en Revista de Derecho Comparado, $\mathrm{N}^{\circ} 1$, "La Reforma de la Codificación Civil en América Latina" por JULIO CÉSAR RIVERA, Rubinzal - Culzoni Editores, Buenos Aires, 2000, págs. 176-177. 
mente con miras a la certeza jurídica. Así en nuestro país lo que es común en los países latinoamericanos, encontramos en su apéndice algunas de estas leyes especiales, otras, figuran en los apéndices de otros cuerpos normativos, pero que también integran el Derecho Privado. Dentro de las primeras podemos anotar cronológicamente entre las más importantes, las siguientes: Ley de Matrimonio Civil de 1884, ${ }^{21}$ Ley $\mathrm{N}^{\circ} 4.808$ sobre Registro Civil de 1930, Ley $\mathrm{N}^{\circ} 17.344$ que Autoriza el cambio de Nombres y Apellidos de 1970; Ley $\mathrm{N}^{\circ} 17.336$ sobre Propiedad Intelectual de 1970; Decreto Ley $N^{\circ}$ 993 sobre Arrendamiento de Predios Rústicos de 1975; Decreto Ley No 2.695 sobre Regularización de la Posesión de la Pequeña Propiedad Raíz de 1979; Ley No 18.010 sobre Operaciones de Crédito de Dinero de 1981; Ley $\mathrm{N}^{\circ} 18.101$ sobre Arrendamiento de Predios Urbanos de 1982; Ley N ${ }^{\circ} 18.112$ sobre Prenda sin Desplazamiento de 1982; Ley No 18.302 sobre Seguridad Nuclear de 1984; Ley No 19.039 sobre Privilegios Industriales y Protección de los Derechos de la Propiedad Industrial de 1991; Ley $N^{\circ} 19.281$ sobre Arrendamiento de Viviendas con Promesa de Venta de 1993; y Ley $\mathrm{N}^{\mathrm{o}} 19.537$ sobre Copropiedad Inmobiliaria de 1997. Otro tanto ha ocurrido con nuestro Código de Comercio que comenzara a regir el $1^{\circ} \mathrm{de}$ enero de 1867 y del cual, queda poco por no decir nada. Así por ejemplo, su Libro IV relativo a la quiebra fue derogado por una Ley especial de Quiebras en el año 1929, después sustituida por la actual Ley $\mathrm{N}^{\circ} 18.175$ de 1982 . Por otra parte encuentra normativa extracodicial el Derecho Bancario, el Derecho Marítimo, los Efectos de Comercio y Valores, las Garantías, la Libre Competencia, etc. En su apéndice encon-

tramos además, la Ley N 19.496 sobre Protección de los Derechos de los Consumidores de 1997

Aparte de esta descodificación enfrentamos la problemática de las sucesivas leyes modificatorias del Código Civil originario dictadas al menos en nuestro país en materia de Derecho de Familia, pues en lo que respecta a Derecho Patrimonial, las modificaciones han sido prácticamente nulas. Como hemos señalado en otra parte de esta presentación, aún no encuentran cabida entre nosotros instituciones tales como la regularización de las cláusulas abusivas, la incorporación de la revisión judicial de los contratos por excesiva onerosidad sobreviniente, la lesión mixta o subjetiva con aplicación general, por señalar algunas. En lo que respecta al Derecho de Familia, el proceso modificador comienza a partir del año 1925 y se paraliza en 1952 para reiniciarse en 1989, y concluir recientemente en 1998 con la instauración de un nuevo estatuto filiativo que a mi juicio, ha dado lugar a una derogación orgánica que recogiendo los principios de igualdad, identidad biológica e interés superior del niño, establece un régimen de libre investigación de la paternidad o maternidad, con la admisibilidad de todos los medios probatorios, y muy especialmente del peritaje biológico de ADN. Sin embargo, entre las materias de Derecho de Familia, muy especialmente en lo que respecta al sistema económico del matrimonio y la autoridad parental o relación filial, la reforma no ha sido integral, de tal manera que hoy nos enfrentamos a un Código parchado y desarmónico, que establece discriminaciones no sólo en razón del sexo, sino que también en lo que respecta a la posición social, específicamente en materia ali-

${ }^{21}$ Sin perjuicio que en la actualidad se tramita una Nueva Ley de Matrimonio Civil (Boletín $\mathrm{N}^{\circ} 1759-18$ ) que aparte de regular las condiciones generales de la celebración del matrimonio, estatuye dentro de la disolución de matrimonio, el divorcio vincular, aparte desde luego de la muerte y la nulidad de éste y la separación de los cónyuges, proyecto al cual, su Excelencia el Presidente de la República le ha dado urgencia, pues como es sabido, el divorcio a la chilena importa un jucio simulado de nulidad matrimonial por incompetencia del Oficial de Registro Civil, y constime el único pás dento Registro Civil, y constituye el unico pais dentro del sistema legal occidental que no contempla el divorcio con disolución de vínculo.

Revista da Faculdade de Direito da UFRGS, v. 20, Outubro/2001 mentaria. Nuestra esperanza ante esta problemática es que en sede judicial, se invoquen y se apliquen los tratados internacionales de derechos humanos, muy especialmente, la Convención sobre Eliminación de todas las Formas de Discriminación contra la Mujer, la Convención de los Derechos del Niño, los Pactos Gemelos y el Pacto de San José de Costa Rica, todos de jerarquía constitucional. Sin embargo, hasta la fecha, siendo manifiesta la inconstitucionalidad del Código Civil, no existe jurisprudencia en la materia.

\section{La constitucionalización de derecho privado o privatiza- ción del derecho constitucional}

Los primeros reconocimiento expresos de los derechos humanos a través de la Carta Magna de 1215, la Declaración de la Independencia Americana de 1776 y 1 Declaración de los derechos del Hombre y de Ciudadano de 1789 se fundaron en la necesidad de proteger a las personas de los excesos de poder. Con los procesos de reforma constitucional gestados durante el siglo pasado se van incorporando a las cartas fundamentales el reconocimiento de los derechos de 1 personalidad, considerados éstos no sólo desde una perspectiva Estado - Individuo, sino que también, de individuos entre sí, surgiendo una Privatización del Derecho Constitucional. Por su parte, los códigos civiles del siglo XIX enfocaron su preocupación fundamentalmente en el área del Derecho Patrimonial, preocupándose del Derecho de las Personas muy incidentalmente, no sólo en cuanto a espacio físico que se les dedica, sino que

${ }^{22}$ DIEZ - PICAZO, LUIS, Lecciones de Derecho Civil I, Parte General, Universidad de Valencia, Facultad de Derecho, Madrid 1967, pág. 327.

${ }^{23}$ Art. 5 también en consideración a la sustancia de las materias tratadas. Así, en los códigos civiles tradicionales interesa la persona sólo incidentalmente a propósito de relaciones jurídicas patrimoniales y se regulan instituciones tales como el estado civil, el domicilio y la capacidad. Frente a esta realidad, van apareciendo los códigos civiles modernos que centrados en el principio según el cual, la persona es el eje fundamental de la preocupación del Derecho, comienzan a regular los derechos de la personalidad, y allí podríamos hablar entonces de la Constitucionalización del Derecho Privado. Sin embargo, es necesario destacar que "la concepción tradicional española, tan favorable a la defensa de todas las manifestaciones de la personalidad nos transmite el principio jurídico de que es ilícito todo ataque o vejación a la persona", y en este sentido, señala DIEZ trato), 1936 (cosas prescriptibles), 865 ( legados), 1116 (condiciones imposibles) y 762 (incapacidad sucesoria) colocan a la persona fuera del trafico jurídico" ${ }^{22}$, principio que sin lugar a dudas encuentra asidero en los códigos civiles del siglo XIX. Pero ya con un reconocimiento explícito de los derechos de la personalidad, más allá de los clásicamente denominados "atributos de la personalidad", es atingente nombrar el Código Civil italiano de 1942, el que en su Libro I "De las personas y de la Familia", Título I, "De las personas físicas", prohibe los actos de disposición del propio cuerpo cuando ocasionasen una disminución permanente de la integridad física o cuando de otra manera sean contrarios a la ley, al orden público o a las buenas costumbres. ${ }^{23}$ Por otra parte, se consagra el derecho al nombre (arts. $6,7,8$ y 9) y se castiga el abuso de la imagen ajena de una persona o de sus padres, cónyuge o hijos en cuanto se haya expuesto o publicado PICAZO, "los artículos 1271 (objeto del con- 
fuera de los casos en que la exposición o la publicación es permitida por la ley, o, con perjuicio para el decoro o la reputación de la persona misma o de los parientes señalados. ${ }^{24}$ Así también, el Código Civil de Portugal de 1977 en su Libro I "Parte General", Título II, Sección II intitulada "Derechos de la personalidad" dispone en forma general, que la ley protege a los individuos contra cualquier ofensa ilícita o amenaza de ofensa a su personalidad física o moral y agrega, que independientemente de la responsabilidad civil a que haya lugar, la persona puede requerir las providencias adecuadas a las circunstancias del caso, con el fin de evitar la consumación de la amenaza o atenuar los efectos de la ya producida. ${ }^{25}$ Ya en forma más específica, reconoce el derecho al nombre y al seudónimo, la privacidad de la correspondencia, el derecho a la imagen y a la intimidad de la vida privada.

En el plano latinoamericano, es de resaltar el Código Civil peruano de 1984 que reconoce entre otros derechos humanos, el de no-discriminación entre varón y mujer, la intimidad personal y familiar, la imagen y voz, el secreto y la reserva de las comunicaciones y el deber y derecho al nombre. ${ }^{26}$ Dentro del proceso de recodificación y modificación de los códigos civiles latinoamericanos es importante destacar en este sentido, las enmiendas propuestas al Libro I del Código Civil peruano por la Comisión de Reforma entre las que puede mencionarse, el tratamiento jurídico del conce-

bido a través de una enmienda didáctica, la capacidad de goce entendida como connatural al ser humano sin que se admitan excepciones; la incorporación de los derechos a la identidad y a la salud; la libertad de someterse a tratamiento médico quirúrgico, la restricción de la capacidad de ejercicio con el fin de humanizar la institución, y muy especialmente el principio de una protección preventiva, integral y unitaria del ser humano. ${ }^{27}$ En este mismo contexto y citando al doctor JULIO CÉSAR RIVERA, vuestro proyecto de Código Civil de 1998, a la luz de la constitucionalización y supranacionalización del derecho general de la personalidad, incluye dentro de la temática la capacidad de derecho, la capacidad de ejercicio, tópico en el cual, acertadamente se estatuye que la interdicción por causas psíquicas no impone una incapacidad necesariamente absoluta, la mayoría de edad a los 18 años siguiendo de esta manera las legislaciones de Brasil, Paraguay, Uruguay y la de Chile que la establece el año 1993 por Ley $\mathrm{N}^{\circ} 19.221$; el discernimiento, el domicilio, y muy especialmente la protección de la personalidad, distinguiendo al efecto entre los derechos de la personalidad espiritual y los derechos a la personalidad física, reconociéndose entre los primeros a la intimidad personal o familiar, honor y reputación, el derecho a la identidad y el derecho a la imagen. Entre los derechos de la personalidad física, se reconoce el derecho a la vida e integridad física desde el momento mismo de la concepción, la regulación de los actos de disposición del propio cuerpo; la prohibición de las prácticas eugenésicas y el tratamiento de la disposición del cadáver. ${ }^{28}$

A modo de conclusión, podemos afirmar certeramente que dentro del proceso recodificador y como una consecuencia de la Constitucionalización del Derecho Privado o Privatización del Derecho Constitucional, como asímismo, de la internacionalización de Derecho Privado hemos arribado a la HUMANIZACION DEL DERECHOPRIVADO.

Considerando que los países que integran el mercosur ya como socios o asociados pertenecen a la familia de derecho romano - germánico, y que por otra parte, comparten una tradición histórica y cultural común, sin perjuicio de las singulares diferenciaciones de cada uno, la integración dentro de la región ha de materializarse no solamente en el área de lo económico, sino que además y en la medida de los esfuerzos y acuerdos que se logren al respecto, en los principios que han de fundamentar el derecho privado del siglo $x x i$ en el deseo de llegar a un derecho privado comunitario. en este sentido, constituye un ejemplo a seguir, los planteamientos y principios que a este respecto se señalan en el acta de arequipa de 1999.

\section{${ }^{24}$ Art. 10}

${ }^{25}$ Art. 70. Es este artículo que informa en gran medida el anteproyecto elaborado por la Comisión de Reformas Legales integrada en esa oportunidad por las profesoras (es) Solange Doyharcabal C., Claudia Schmidt H. y Francisco Merino S. de la Universidad Gabriela Mistral sobre "Protección a los Derechos de la Personalidad" publicado en la Revista Temas de Derecho, Volumen VI No 2 de Julio-Diciembre de 1991.

${ }^{26}$ Libro I "De las Personas", Sección Primera, "De las Personas Naturales" arts. 1 y ss.

${ }^{27}$ Ver FERNÁNDEZ SESSAREGO, CARLOS, Derecho de las Personas, Enmiendas propuestas al Libro Primero del Código Civil sobre el Derecho del concebido y de las personas naturales con breve Referencia al Proyecto de Código Civil de la República Argentina de 1998, en: El Código Civil del Siglo XXI, ob. Cit. en nota 14 pág. 181 y ss.

${ }^{28}$ Ver El Código Civil del Siglo XXI, Tomo II, ob. cit. en nota 14 págs. 993 y ss. 